\title{
O Arquivo Público enquanto lugar de memória
}

\author{
Maria Juvanete Ferreira da Cunha Pereira*
}

\begin{abstract}
RESUMO: O texto visa trabalhar o Arquivo Público do Distrito Federal enquanto lugar de memória, constituído com a finalidade de preservar determinadas memórias, procurando compreender os critérios adotados pela instituição na seleção do que deve ser preservado sobre a memória da nova capital. Procura perceber o papel do arquivo não apenas como guardião, mas também como produtor de memória, o que é feito muito claramente pelos projetos de história oral que desenvolvem, e neste sentido, faz uma análise do Projeto Memória da Construção de Brasília.
\end{abstract}

Palavras-chave: lugar de memória, Arquivo Público do Distrito Federal, história oral.

Abstract: The paper's aim is to work on the Federal District Public File with regard to the place of memory, constituted with the purpose of preserving determined memories, seeking to understand the criteria adopted by the institution in the selection of what must be preserved about the memory of the new capital. The perception of the role of the file was sought, not only as a guardian, but also as a memory producer, which is very clearly done by the oral history projects that are developed and as such, make an analysis of the Memory of the Construction of Brasilia Project.

Keywords: place of memory, Federal District Public File, oral history.

Este texto analisa a memória enquanto prática no Arquivo Público do Distrito Federal, procurando compreender quais as teorias de memória estariam informando os organizadores do arquivo e que resultaram na elaboração do Projeto Memória da Construção de Brasília. Ver o Arquivo enquanto lugar de memória, constituído com a finalidade de preservar determinadas memórias.

Para tanto foi necessário trabalhar num primeiro momento as teorias de memória que nortearam a análise. Nesse ponto trabalha-se a relação entre memória e história, o conceito de lugares de memória, que é observado neste trabalho como uma categoria apropriada pela política de preservação na década de 1980, que influencia a criação do Arquivo, e ainda a relação entre lugares de memória e enquadramento de memória para servir de base e saber como o Arquivo enquadra a memória que deseja tornar coletiva.

\footnotetext{
* Professora de História da Rede Pública do Distrito Federal e do Colégio Militar de Brasília, Mestre em Gestão Econômica do Meio Ambiente e Especialista em História Cultural: Identidades, Tradições, Fronteiras Universidade de Brasília - UnB. juvanete@yahoo.com.br
} 
Em seguida é feito um resgate histórico da fundação do Arquivo, como também um relato de sua principal composição, seu acervo e uma apresentação e análise do Programa de História Oral com a finalidade de, a partir desses dados, conhecer a dimensão e os objetivos do Arquivo.

\section{História e Memória}

A História Cultural constitui como objeto de pesquisa, a percepção dos indivíduos no tempo, seus valores, aspirações, modelos, ambições e temores. Visa atingir as percepções individuais e coletivas, que os homens constroem sobre o mundo. Interessa-se pelos sujeitos produtores e receptores de cultura. ${ }^{1}$ A memória, obviamente, nunca está toda escrita. A problemática da memória tem recebido uma atenção privilegiada das ciências humanas nos últimos anos, é algo da vida. E como não há vida sem expectativas, não é o passado que dá sentido ao presente. São as expectativas de futuro que dão sentido ao passado. E por isso a memória é dinâmica, porque faz parte da vida. "A história e a memória são representações narrativas que se propõem uma reconstrução do passado e que se poderia chamar de registro de uma ausência no tempo". 2

Não é difícil perceber a existência de uma relação aparentemente natural entre esses dois campos, já que para fazer história se está permanentemente recorrendo à memória, e ao mesmo tempo ao fazer história constroe-se uma memória para o futuro. A relação entre os dois campos é de tal forma direta que permite a confusão dos conceitos e a indefinição dos limites de quando uma lembrança deixa de ser memória e torna-se história. Esse é um dos grandes debates teóricos, pois envolve os objetivos e fundamentos do trabalho histórico. Atualmente, a maioria dos autores concorda que a memória não pode ser vista simplesmente como um processo parcial e limitado de lembrar fatos ${ }^{3}$. Trata-se da construção de referenciais sobre o passado e o presente de diferentes grupos sociais, ancorados nas tradições e intimamente associados a mudanças culturais. Há também um consenso de que a história não tem mais a pretensão de estabelecer os fatos como realmente aconteceram. O passado pode ser observado e narrado de diferenciadas formas. Um fato concreto pode suscitar diversas memórias, depende de como foi registrado no tempo próximo de seu acontecimento e, principalmente, do tempo de quem o relembra, de quem o relê e o reconta. Como afirma Michael Pollak, a memória é "uma operação coletiva dos acontecimentos e das interpretações do passado que se quer salvaguardar". ${ }^{4}$ E aqui importa destacar que a memória é sempre um 
processo coletivo, pois mesmo aquela mais peculiar a cada indivíduo se compõe de elementos constituídos socialmente e da mesma forma recuperados das sombras do que passou pelo foco de luz acionado por estímulos comunitários. Tanto na sua matéria-prima como na sua motivação, a memória é obra da coletividade, mesmo que seja individual.

Maurice Halbwachs destaca que pela memória o passado vem à tona, misturando-se com as percepções imediatas, deslocando-as, ocupando todo o espaço da consciência. Afirma também que a natureza da lembrança é social e que ela nos aparece, por efeito de várias séries de pensamentos coletivos, e se não for atribuída exclusivamente a estes, ela se torna independente, mas necessita de um apoio por si só para se sustentar. Estudos empreendidos por ele contribuíram definitivamente para a compreensão dos quadros sociais que compõem a memória. Para ele a memória aparentemente mais particular remete a um grupo. O indivíduo carrega em si a lembrança, mas, está sempre interagindo com a sociedade, seus grupos e instituições. Considera que a memória coletiva envolve memórias individuais, mas não se limita a elas. As memórias individuais são mais densas e contínuas, sendo que a memória coletiva é mais ampla, resumida e esquemática. $\mathrm{O}$ autor estabelece que a memória emerge em função de um grupo que a ela se devota, sendo tão plural quanto plural seja a sociedade em sua configuração socioeconômica, cultural e política. Cada grupo produz e atualiza a sua memória de acordo com seus interesses presentes e projetos futuros. ${ }^{5}$

Destaca-se também que memória não é algo pronto e acabado, cristalizado. No processo dinâmico de constituição, eliminam-se interesses, estabelecem-se novos jogos de poder, cambiam-se os conteúdos da lembrança e do esquecimento, sempre formados pelos atores do presente, com base num repertório passado, com vistas a um futuro imaginado, desejado. E aqui vale salientar a visão dele de que a memória não tem passado, sobrevivendo enquanto seus personagens vivem ou se lembram. ${ }^{6}$

Para Nora a separação entre memória e história na sociedade contemporânea produz significados bem definidos. A memória é tida como tradição definidora, portadora de uma herança que dá sentido e forma, ela é viva e dinâmica. Nora chega a afirmar que ela é "ditatorial e inconsciente de si mesma, organizadora e toda poderosa, espontaneamente atualizadora, uma memória sem passado que reconduz eternamente a herança, conduzindo o antigamente dos ancestrais ao tempo indiferenciado dos heróis, das origens e dos mitos", é como se ela, enquanto narrativa, tendesse a cumprir o papel que o mito tem nas sociedades 
tradicionais, ou seja, fundamentar e organizar. ${ }^{7}$ Mas não se pode esquecer que a própria memória é seletiva, já que não se pode lembrar de tudo que aconteceu.

A memória é seletiva. Nem tudo fica gravado. Nem tudo fica registrado. A memória é, em parte, herdada, não se refere apenas à vida física da pessoa. A memória também sofre flutuações que são função do momento em que ela é articulada, em que ela está sendo expressa. As preocupações do momento constituem um elemento de estruturação da memória. Isso é verdade também em relação à memória coletiva, ainda que esta seja bem mais organizada. Todos sabem que até as datas oficiais são fortemente estruturadas do ponto de vista político. ${ }^{8}$

Jacques Le Goff aponta que os conceitos de memória e história tendem a se confundir até os dias de hoje. Esse autor lembra que, como leitura do real, a história é sempre construção da memória coletiva, e nela, como em toda memória, entrecruzam-se o objetivo e o subjetivo; o registro e a criação; a lembrança e o esquecimento. Ou seja, a memória não é somente lembrança e esquecimento, ela é também - e principalmente - uma construção. ${ }^{9}$

Filosoficamente memória significa a capacidade de reter um dado da experiência ou conhecimento adquirido e trazê-lo à mente; e esta é necessária para constituição das experiências e do conhecimento científico. Toda produção do conhecimento se dá a partir de memórias de um passado que é consolidado no presente. Para Marieta Ferreira "a memória é também uma construção do passado, mas pautada em emoções e vivências; ela é flexível, e os eventos são lembrados à luz da experiência subseqüente e das necessidades do presente". 10

É no contexto destas relações que se constroem as lembranças. A rememoração individual está impregnada das memórias dos que estão em volta e as lembranças se alimentam das diversas memórias oferecidas pelo grupo e dificilmente as lembranças são afloradas fora deste quadro de referências. Tanto nos processos de produção da memória como na rememoração, o outro tem um papel fundamental. Esta memória coletiva tem assim uma importante função de contribuir para o sentimento de pertinência a um grupo de passado comum, que compartilha memórias. Ela garante o sentimento de identidade do indivíduo calcado numa memória compartilhada não só no campo histórico, do real, mas, sobretudo, no campo simbólico.

A memória se modifica e se rearticula conforme a posição que o indivíduo ocupa e às relações que são estabelecidas nos diferentes grupos de que participa. Também está submetida a questões inconscientes, como o afeto, a censura, entre outros. As memórias individuais 
alimentam-se da memória coletiva e histórica e incluem elementos mais amplos do que a memória construída pelo indivíduo e seu grupo. Um dos elementos mais importantes, que afirmam o caráter social da memória é a linguagem. As trocas entre os membros de um grupo se fazem por meio de linguagem. Como afirma Ecléa Bosi a linguagem é o instrumento que socializa a memória, pois reduz, unifica e aproxima, no mesmo espaço histórico e cultural, vivências tão diversas como o sonho, as lembranças e as experiências recentes. ${ }^{11}$

É interessante ainda apontar que a memória é um objeto de luta pelo poder, travada entre classes, grupos e indivíduos. Decidir sobre o que deve ser lembrando e também sobre o que deve ser esquecido integra os mecanismos de controle de um grupo sobre o outro. Desse embate resultam, entre outras, o que será lembrado, que datas receberão atenção e comemoração, que histórias, consideradas importantes para todos deverão integrar os arquivos de memória.

Koselleck trabalha com a noção de espaço de experiência e horizonte de expectativa. $\mathrm{Na}$ experiência estão reunidos extratos de tempos anteriores; no horizonte se abre um novo espaço de experiência. O que se espera do futuro está limitado ao que se sabe do passado. Os acontecimentos da época da construção de Brasília, trabalhados pelo Arquivo, fazem parte do passado, porém, as experiências baseadas neles podem modificar-se com o tempo. As experiências se sobrepõem, se impregnam umas as outras, novas esperanças ou desenganos, novas expectativas, abrem brechas e repercutem nelas. Assim também as experiências se modificam e sempre pressupõem uma experiência precedente. ${ }^{12}$

Fernando Catroga fala que a memória sempre está ameaçada pela amnésia e só poderá desempenhar a sua função social através de liturgias próprias, centradas em reavivamentos que só os traços, vestígios do passado são capazes de provocar. Portanto o seu conteúdo é inseparável dos seus campos de objetivação e de tratamento. Não haverá memória coletiva sem suporte de memória, ritualisticamente compartilhada. A raiz da memória mergulha num "espaço de experiência" aberto tanto a recordação como às expectativas, horizonte que o recebe como herança e como possibilidade de se perpetuar. ${ }^{13}$

\section{Lugares de Memória e Enquadramento da Memória}

A possibilidade de resgatar a memória do passado através de lugares de memória e objetos que os rodeiam empresta uma sensação de segurança, de poder ir e vir dentro do 
universo das lembranças; assegura um sentimento de identidade com as raízes. Os objetos materiais representam a garantia da permanência através do tempo. Os lugares de memória como o Arquivo Público do Distrito Federal, apontam para esta reflexão: o desejo de permanência, de guardar a memória da cidade desde a sua construção. As memórias individual e coletiva têm nos lugares, uma referência importante para a sua construção, ainda que não sejam condição para a sua preservação. As memórias dos grupos se referenciam, também, nos espaços em que habitam e nas relações que constroem com estes espaços.

Segundo Pollak existem lugares da memória, lugares particularmente ligados a uma lembrança, que pode ser uma lembrança pessoal, mas também pode não ter apoio no tempo cronológico. Pode ser, por exemplo, um lugar da infância, que permaneceu muito forte na memória da pessoa, muito marcante, independentemente da data real em que a vivência se deu. Na memória mais coletiva pode haver lugares de apoio da memória, que são os lugares de comemoração. A construção da cidade, os monumentos, por exemplo, podem servir de base a uma relembrança de um período que a pessoa viveu por ela mesma, ou de um período vivido por tabela, onde a pessoa não viveu pessoalmente, mas faz parte de sua memória em função da memória do grupo. ${ }^{14}$

A transmissão de vivências individuais e coletivas se perdeu no cenário contemporâneo. Segundo Nora, as sociedades primitivas não tinham necessidade de lugares de memória porque nelas a memória ainda estava viva, sendo transmitida oralmente de geração em geração. Cada gesto, cada fazer no cotidiano, possuía seu significado e seu ritual. O fenômeno moderno da aceleração faz como que o próprio presente se torne cada vez mais volátil, havendo uma espécie de presunção de que seria possível unificar o que se passa no mundo. A consequiência mais imediata deste fenômeno seria a perda das características particulares do homem, daí a necessidade de se criar em profusão "santuários de memória". Sendo assim, Nora apresenta sua categoria de "Lugares de Memória" como resposta a essa necessidade de identificação do indivíduo contemporâneo. Ele afirma que os lugares de memória nascem da consciência de que não há memória espontânea, é preciso criar arquivos. E esses arquivos têm significâncias materiais, funcionais e simbólicas, são variados, de registros escritos, orais, coleção de fotografias, datas comemorativas, passando por celebrações e símbolos, até museus, bibliotecas e obras de arte. É preciso manter aniversários, organizar celebrações e pronunciar elogios. ${ }^{15}$ 
De acordo com esse ponto de vista a velocidade da vida diária torna necessária à existência, ou à produção, lugares de memória. Lugares portadores de história, de significado que, de outra forma, se perderia. No entanto, deve-se retomar a história individual e coletiva no sentido de reestruturar o presente, restabelecer a espessura perdida com o esvaziamento de significado do dia-a-dia. Pois o olhar desatento e apressado condena até mesmo os lugares de memória ao esquecimento. Como diz Nora, "a memória se enraíza no concreto, no espaço, no gesto, na imagem, no objeto". ${ }^{16}$ Ao contrário do que se pensa, a memória não chega pronta, ela é construída, cultuada e mantida através do real desejo e empenho daqueles que as precedem. Cabe a cada um reconstruí-la a partir do presente para transmiti-la, já outra, aos que virão. $^{17}$

Um lugar de memória é um núcleo significativo, tanto material como imaterial, e de larga duração através das gerações, para a memória e as identidades coletivas. Este núcleo se caracteriza por uma forte carga de simbolismo o de emoção. Está arraigado nas convenções e costumes sociais, culturais e políticos e se modifica na medida em que mudam as maneiras de sua concepção, aprovação, uso e tradição. Os lugares de memória são estabilizadores da memória coletiva. Le Goff comenta sobre a história que fermenta a partir do estudo dos lugares da memória coletiva e cita Pierre Nora:

Lugares topográficos como os arquivos, as bibliotecas, os museus; lugares monumentais como os cemitérios ou as arquiteturas, lugares simbólicos como as comemorações, as peregrinações, os aniversários ou os emblemas; lugares funcionais como os manuais, as autobiografias ou as associações: estes memoriais têm sua história. ${ }^{18}$

São os lugares de externalização da memória, onde a memória se apresenta nas coisas, nas manifestações coletivas mostrando que são muitos os sentidos de memória e são muitos os sentidos de lugares da memória. O historiador se vê com a tarefa de reconstruir o que "não existe mais", o que se configura em um movimento que é sempre problemático e incompleto, e que só pode proporcionar uma representação do passado.

O resgate da memória é de suma importância devido à construção de uma identidade consistente, para isso é necessário que não deixe de rememorar, ir a busca das raízes, das origens, do âmago da sua história. A memória tem um caráter primordial para elevação de uma nação, pois aporta elementos para sua transformação, sendo um elemento essencial na constituição da identidade individual, coletiva e institucional. Não se pode esquecer, no entanto, que a memória não é apenas uma conquista de indivíduos ou coletividades, é também 
um instrumento e um objeto de poder. ${ }^{19}$ As práticas mnemônicas da contemporaneidade espelham lutas e negociações pelo domínio da recordação e do passado. Como já explicitou Michel Pollack, toda memória pressupõe enquadramentos, esquecimentos e silêncios. ${ }^{20}$ As memórias não são restituições fiéis do passado, mas reconstruções, continuamente atualizadas e re-configuradas. As memórias, assim como as identidades, são construções sociais e não objetos naturais, não são fatos que possam ser tratados fora da linguagem que as formulam e as dinamizam. Segundo Pollak, os elementos constitutivos da memória, são os acontecimentos vividos pessoalmente e os acontecimentos vividos pelo grupo ou pela coletividade à qual a pessoa se sente pertencer. São acontecimentos que a pessoa nem sempre participou, mas, que, no imaginário, tomaram tamanho relevo que, no fim das contas, é quase impossível que ela consiga saber se participou ou não. É perfeitamente possível que, por meio da socialização política, ou da socialização histórica, ocorra um fenômeno de projeção ou de identificação com determinado passado, tão forte que se pode falar numa memória quase que herdada. Além desses acontecimentos, a memória é constituída por pessoas e personagens. ${ }^{21}$

A identidade cultural e a memória reforçam-se mutuamente. Conhecendo as raízes, é fácil distinguir o que une e o que divide e então, aptos a entender que a cultura e a memória são faces de uma mesma moeda e que a atitude cultural, por excelência aliada ao que está em volta, desde os testemunhos construídos ou das expressões da natureza aos testemunhos vivos são imprescindíveis para a construção desta identidade. Stuart Hall afirma que:

O sujeito assume identidades diferentes em diferentes momentos, identidades que não são unificadas ao redor de um "eu” coerente. Dentro de nós há identidades contraditórias, empurrando em diferentes direções, de tal modo que nossas identificações estão sendo continuamente deslocadas. ${ }^{22}$

A identificação é construída a partir do reconhecimento de alguma origem comum, ou de características que são partilhadas com outros grupos ou pessoas, ou ainda a partir de um mesmo ideal As identidades parecem invocar uma origem que residiria em um passado histórico com o qual elas continuariam a manter uma certa correspondência.

A valorização de uma história das representações, e da compreensão dos usos políticos do passado pelo presente promoveu uma reavaliação das relações entre história e memória e permitiu aos historiadores repensar as relações entre passado e presente e definir para a história do tempo presente, o estudo dos usos do passado. A memória é também uma 
construção do passado, mas pautada em emoções e vivências; ela é flexível, e os eventos são lembrados à luz da experiência subseqüente e das necessidades do presente.

\section{História Oral}

A história oral se situa, em meio ao desenvolvimento dos métodos qualitativos de investigação. A oralidade permite obter e desenvolver conhecimentos novos e fundamentar análises históricas com base na criação de fontes inéditas ou novas. Ao se interessar pela oralidade, a História procura destacar e deixar como centro de sua análise a visão e versão das experiências mais profundas dos seus atores sociais. A coleta de depoimentos pessoais mediante a utilização de um gravador iniciou-se na década de 1940 nos Estados Unidos. A expansão desse processo teve lugar apenas na segunda metade dos anos 60, prolongando-se ao longo da década de 1970, procurando dar voz aos excluídos, recuperar as trajetórias dos grupos dominados, tirar do esquecimento o que a história oficial sufocara durante tanto tempo. As lutas pelos direitos civis, travadas pelas minorias de negros, mulheres, imigrantes etc., seriam as principais responsáveis pela afirmação da história oral. A história oral se afirmava, assim, como instrumento de construção de identidade de grupos e de transformação social. $^{23}$

A História Oral passa a ser mais do que uma decisão técnica ou de procedimento, nem apenas é um roteiro para o processo detalhado e preciso de transcrição da oralidade. Com a utilização da História Oral, ocorreu a conquista de espaços que possibilitaram uma reflexão em relação ao presente-passado e também, complementou dados documentais da história até então analisada. Além disso, é possível resgatar a vida cotidiana mantida na memória. As transformações recentes ocorridas no campo da história em geral, e na história do século XX, em particular, geraram uma nova discussão sobre o papel das fontes históricas, permitindo que a história oral ocupe um novo espaço nos debates historiográficos atuais. Em primeiro lugar, com a história do tempo presente, portadora da singularidade de conviver com testemunhos vivos que sob certo aspecto condicionam o trabalho do historiador, coloca obrigatoriamente em foco os depoimentos orais. ${ }^{24}$

A História Oral registra emoções e sentimentos de pessoas das mais diversas origens sócio-culturais. Segundo Pollak, a História Oral, ao privilegiar a análise dos excluídos, das minorias, ressaltou a importância das memórias subterrâneas, que cria o seu processo de 
subversão no silêncio e acaba aflorando em momentos de crise, e assim, o longo silêncio sobre o passado, longe de conduzir ao esquecimento, é a resistência que uma sociedade civil impotente opõe ao excesso de discursos oficiais. ${ }^{25}$

\section{Origem e composição do Arquivo Público do Distrito Federal}

No final da década de 80, após o início do processo de redemocratização do país, da nova Constituição de 1988 e de eleições diretas para presidente, depois de mais de 20 anos, houve um incentivo à abertura de programas institucionais que atuaram como elementos dinamizadores para a pesquisa sobre a história recente do Brasil com reflexos sobre a História Oral. Nasceram novos centros de pesquisas, uns ligados às universidades e outros localizados em instituições de pesquisa fora das universidades. O Arquivo Público do Distrito Federal nasceu com uma definição prévia e fechada de sua linha de acervo, voltou-se para o recebimento de arquivos completos, visando atender uma comunidade mais ampla de usuários. Neste tipo de pesquisa, os programas de História Oral constituem apenas uma das atividades existentes.

O Arquivo Público do Distrito Federal, criado pelo Decreto $n^{\circ}$ 8.530, de 14 de março de 1985, tem a função de recolher, preservar e garantir proteção especial à documentação arquivista de valor permanente do Distrito Federal, em toda sua extensão, visando estimular e facilitar a realização de pesquisas. Em 1970 o Governo do Distrito Federal foi signatário do documento Compromisso de Brasília, fruto do encontro de governadores de Estado que elaboraram estudos sobre o Patrimônio Histórico e Artístico Nacional. O documento recomendava o apoio do Arquivo Nacional às repartições congêneres estaduais e municipais relativas à preservação dos acervos documentais. ${ }^{26}$

O I Congresso Brasileiro de Arquivologia, em 1972, sugeriu que o GDF criasse o seu Arquivo Público, integrando-o ao movimento de preservação da memória nacional, que se ampliava em todo o Brasil. Em 27 de abril de 1983, através do Decreto n 7.493 , criou-se o grupo para a implantação do Arquivo. Finalmente, em 14 de março de 1985, o Decreto no 8.530 cria o Arquivo e em 2000, é aprovada a Lei $n^{\circ} 2.545$, que dispõe sobre a proteção dos documentos de arquivos públicos, definindo-o como instituição arquivistica pública do Poder Executivo e colocando-o como órgão central do Sistema de Arquivos do Distrito Federal SIARDF. ${ }^{27}$ 
O Arquivo "conta com uma área de $1200 \mathrm{~m}^{2}$, possuindo uma mapoteca (plantas aerofotogramétricas, cartas topográficas dos sítios e mapas diversos), um laboratório fotográfico, uma sala de consultas, salas climatizadas cujo controle é feito através de desumidificadores, ar condicionado e termohigrógrafos. O controle da luminosidade é realizado por meio de películas nos vidros. A higienização da documentação, a limpeza dos depósitos e os procedimentos técnicos arquivísticos são empreendidos em prol da conservação preventiva". ${ }^{28}$

Os patrimônios - desde que assumidos - têm uma função social interessante: fazer existir uma entidade coletiva, sempre abstrata, tornando-a visível metaforicamente por exposição pública dos bens que possuíam em comum. No caso do Arquivo Público do Distrito Federal julga-se que ele pode contribuir para que o cidadão, ao reconhecer um determinado elemento esteja a aprofundar a consciência da sua identidade coletiva de cidadãos brasilienses, enquanto construtores de sua própria cidade, feitos realizados que compõem a sua própria história.

O Arquivo Público do Distrito Federal reúne, principalmente, a documentação que retrata a história da Capital Federal, desde as primeiras ações a partir da Constituição de 1892, que previa a interiorização da capital, abarcando desde a construção da cidade, a inauguração até os dias atuais. $\mathrm{O}$ acervo apresenta documentos em diferentes suportes e formatos podendo ser textuais, audiovisuais, cartográficos, dentre outros. Compõem o acervo sete Fundos Públicos e três Fundos Privados. Entende-se por fundo o conjunto de documentos, de qualquer natureza ou suporte, acumulado em decorrência das atividades e/ou funções do poder público ou particular. Além dos documentos de valor permanente, acumulados pelos órgãos do Governo do Distrito Federal, o Arquivo pode recolher a documentação de caráter privado, quando o acervo for considerado relevante para história do Distrito Federal e não houver outra solução viável para sua preservação ou acesso. ${ }^{29}$

Os fundos púbicos são: Fundo da Companhia Urbanizadora da Nova Capital NOVACAP com 458,08 metros lineares de documentação textual, 91 unidades filmicas, 01 fita magnética, 1.646 mapas e plantas, 41 fotos mosaicos, 6.357 negativos e cópias contato, 1.712 ampliações fotográficas, 2.463 diapositivos e 1.114 rolos de microfilmes de um período entre 1892 e 1976. Nessa documentação estão incluídas as cadernetas da Missão Cruls, atas e resoluções, relatórios técnicos, documentação financeira e fiscal, folhas de pagamentos das empreiteiras, dossiês funcionais, projetos e plantas, recortes de jornais, vídeos, filmes e 
fotografias sobre a construção de Brasília, incluindo obras, personalidades do governo, pessoas anônimas e visitantes. A NOVACAP foi criada em 1956, sendo seu objetivo inicial o planejamento, a execução dos serviços de localização, urbanização e construção da Futura Capital. O recolhimento do acervo foi realizado em 1987, tendo em destaque os Diários de Campo do Engenheiro Hastimphilo de Moura, da Comissão Exploradora do Planalto Central 1892 - 1894, responsável pela demarcação do Quadrilátero onde seria fixada a nova Capital da União. ${ }^{30}$

O Fundo da Secretaria de Comunicação Social é oriundo da Secretaria de Comunicação Social que foi criada através da lei $n^{\circ} 7.456$, de $1^{\circ}$ de abril de 1986. O Arquivo recolhe ao final de cada período de governo, o acervo fotográfico e videográfico produzidos pela Secretaria. È possível encontrar imagens do desenvolvimento da cidade de Brasília como: o sistema de viação, obras, saúde, educação, segurança pública, cultura, serviços sociais, finanças, regiões administrativas e solenidades dos prefeitos de Brasília e governadores do Distrito Federal. ${ }^{31}$

O Fundo da Secretaria se Segurança Pública composto pela produção do Centro de Inteligência da Secretaria de Segurança Pública do Distrito Federal, que produziu e acumulou no período de 1967 a 1989, documentos de conteúdo e caráter policial, sobre crimes, segurança pública, atividades e militância política. Em 1995 essa documentação foi recolhida ao Arquivo que é composto por formulário de entrada de dados e dossiês sobre crimes, segurança pública, atividades e militância política. ${ }^{32}$

Fundo da Fundação Cultural do Distrito Federal. A Fundação Cultural do Distrito Federal foi instituída em 27 de janeiro de 1961. Primeiramente recebeu o nome de Fundação Cultural de Brasília e posteriormente alterado para Fundação Cultural do Distrito Federal. A documentação resultante foi recolhida ao Arquivo nos anos de 1997 e 1998. É composto por documentação textual como recorte de jornais, documentos administrativos, projetos, estudos e pesquisas referentes à atividade cultural; documentação iconográfica referente a cinema, dança, música, teatro, literatura, artes plásticas, projetos e diversos eventos promovidos e patrocinados pela Fundação Cultural. ${ }^{33}$

Fundo Gabinete do Governador. Depois da inauguração de Brasília, em 21 de abril de 1960, Israel Pinheiro, foi indicado para o cargo de $1^{\circ}$ prefeito de Brasília. Posteriormente outros 11 prefeitos exerceram o cargo. Em 1969 a Emenda Constitucional no 01 de 17 de outubro altera a condição jurídica, política e administrativa da Prefeitura, transformando-a em 
Governo do Distrito Federal. Documentos referentes aos períodos de 1960 a 1985 e 1995 a 1998, foram recolhida em 1998. Nesta documentação é possível encontrar correspondências, roteiros de solenidade, convites, portarias normativas, boletins de serviço, exposição de motivos, decretos executivos e de pessoal, relatórios e pareceres, relação de funcionários do quadro e provisórios até $1969 .^{34}$

Fundo Arquivo Público do Distrito Federal. Em 28 de abril de 2000 se torna, por meio do Decreto 24.205, Órgão Central do Sistema de Arquivo, sendo responsável pela normalização de procedimentos arquivísticos. Contem antecedentes da instituição; projetos e relatórios das atividades desenvolvidas; estudos e projetos técnicos; documentos contábeis e de pessoal; documentos contendo registros fotográficos e videográficos de eventos realizados pela instituição. ${ }^{35}$

Fundo da Administração Regional de Taguatinga criada em junho de 1958. Em 1995, parte da sua documentação acumulada foi recolhida ao Arquivo Público do Distrito Federal. Documentos sobre o histórico da cidade; históricos e discursos de alguns de seus administradores; ofícios; relatórios técnicos e administrativos; documentação sobre pessoal; contratos e convênios; recortes de jornais; projetos e programas sociais; terminais de transporte, feiras e bancas de jornais; esporte; inaugurações; projetos e diários de obras. ${ }^{36}$

E os fundos privados: Fundo Yvone Jean. Ela, nascida na Bélgica, mudou-se para o Brasil em 1940, morou no Rio de Janeiro e São Paulo, transferiu-se para Brasília em 1962, a convite de Darcy Ribeiro, para lecionar na Universidade de Brasília. Atuou como Jornalista, Escritora, Intérprete e Promotora cultural. Sua casa funcionou como ponto de encontro de intelectuais, e militantes políticos. Ligada ao Partido Comunista Brasileiro, foi condenada a prisão durante o regime militar, faleceu em março de 1981. Em agosto de 1987 a documentação foi recolhida ao Arquivo, por meio de doação feita pelo seu filho João Luiz da Fonseca. Esse acervo é um registro das atividades intelectuais desenvolvidas por Yvone Jean, abrangendo assuntos políticos, sociais, culturais, aspectos familiares e amigos. ${ }^{37}$

Fundo Juca Chaves. José Ferreira de Castro Chaves nasceu em Pernambuco no ano de 1912. Mudou-se, em 1926, para o Rio de Janeiro, onde estudou engenharia. Foi diretor técnico e sócio da Empresa de Construções Gerais - ECG. Em Brasília, integrou-se ao grupo de Juscelino Kubitschek que viabilizou a construção do Catetinho. Participou da construção da Granja do Ipê, do prédio do Banco do Brasil e da SQS $^{38}$ 108. Composto por documentos contendo registros fotográficos de obras e eventos. ${ }^{39}$ 
Fundo Brasília Palace Hotel. As obras começaram em setembro de 1957 e foi inaugurado em 30 de maio de 1958, foi a primeira obra definitiva concluída na Nova Capital. Inicialmente, era conhecido como Hotel de Turismo. O fundo é composto de documentos acumulados pela empresa Prudência de Grandes Hotéis S.A. A documentação é composta por documentação administrativa; contratos; contabilidade; fichas e livros de hospedes; dossiês funcionais; folhas de pagamento e documentos pessoais do proprietário da empresa arrendatária do prédio. ${ }^{40}$

O acervo ainda comporta uma biblioteca especializada em arquivologia, história do Distrito Federal e cidades do entorno. Serve para apoio aos funcionários do Arquivo, na realização das atribuições técnicas de suas unidades orgânicas, além de usuários regionais, nacionais e internacionais. Realiza a normalização técnica das publicações editadas pelo Arquivo e possui 3.191 publicações. Destacam-se: relatórios técnicos das comissões Cruls e Belcher, coleção Brasília editada pelo serviço de documentação da presidência da república, uma coleção depositária composta por relatórios, projetos e publicações do Arquivo, formando a memória intelectual do órgão. ${ }^{41}$

Há também uma coleção de periódicos com uma base de dados PUBSER possui 325 periódicos. Dentre eles destacam-se: a Revista BRASÍLIA, editada pela NOVACAP, composta por 84 números, publicada no período de 1957 a 1988, resgata a história da construção de Brasília (1957-1960), sua inauguração (21 de abril de 1960) e consolidação e a Revista ACERVO do Arquivo Nacional. O acervo de periódicos possui 116 títulos com aproximadamente 500 fascículos. ${ }^{42}$

Um outro tipo de documento que também está acessível no Arquivo são as declarações de tempo de serviço, reconhecidas pelo INSS para fins de aposentadoria, são fornecidas gratuitamente aos trabalhadores que prestaram serviços às empreiteiras contratadas pela NOVACAP, no período da construção de Brasília, após a pesquisa e a confirmação do nome do pioneiro nas folhas de pagamento.

\section{O Programa de História Oral}

O Arquivo Público do Distrito Federal busca resgatar a história do Distrito Federal por meio de Projetos de Pesquisa e do Programa de História Oral que desde 1987, colhe depoimentos de pioneiros que participaram da formação de Brasília e de pessoas que podem 
testemunhar sobre acontecimentos, conjunturas, modos de vida e outros aspectos da história contemporânea. "Os depoimentos são colhidos a partir das entrevistas e na realização de uma entrevista é importante ter conhecimento do objeto de estudo e tornar o momento agradável ao entrevistado, para que seja alcançado o objetivo." 43

A história oral praticada pelo Arquivo é uma história temática. A História Oral temática quase sempre equivale ao uso da documentação oral da mesma maneira que das fontes escritas. Valendo-se do produto da entrevista como mais um outro documento, compatível com a necessidade de busca de esclarecimentos, e o grau de atuação do entrevistador como condutor dos trabalhos fica muito mais explícito. Dado seu caráter específico, a História Oral temática tem características bem diferentes da História Oral de vida. Detalhes da história pessoal do narrador apenas interessam na medida em que se revelam aspectos úteis à informação temática central. A História Oral temática admite a utilização de questionários e estes se tornam peças fundamentais para a aquisição dos detalhes procurados.

$\mathrm{O}$ trabalho compreende todo um conjunto de atividades anteriores e posteriores à gravação dos depoimentos. Exige antes da pesquisa, o levantamento de dados para a preparação dos roteiros das entrevistas. Depois é feita a codificação da língua falada para a escrita, ou seja, é a aproximação da língua falada, mas, obedecendo a ortografia oficial. O trabalho de transcrição é um dos mais cansativos e requer elevado grau de concentração. Logo após vem a correção final que consiste na aplicação das normas internas do Programa de História Oral, adotadas para a confecção do texto a partir da transcrição. Os depoimentos são disponíveis em: Texto, CDs e fitas k-7. ${ }^{44}$ Aqui a pesquisa visa a constituir um acervo de depoimentos aberto ao público, daí ser necessário cuidar da duplicação das gravações, da conservação e do tratamento do material gravado.

As entrevistas são tomadas como fontes para a compreensão do passado, ao lado de documentos escritos, imagens e outros tipos de registro, não como retrato fiel do passado, tal como efetivamente ocorreu e sim como uma versão do entrevistado, uma versão do passado, que podem ser consultadas e avaliadas em qualquer tempo, justamente porque se tem o recurso do gravador. Caracterizam-se por serem produzidas a partir de um estímulo, pois o pesquisador procura o entrevistado e lhe faz perguntas, no caso do Projeto Memória da Construção de Brasília, relacionadas com a construção da cidade. 
A história oral amplia o conhecimento sobre acontecimentos e conjunturas do passado, através do estudo de experiências e versões particulares, procurando compreender a sociedade através do indivíduo, estabelecer relações entre o geral e o particular através da análise comparativa de diferentes versões e testemunhos.

O Programa de História Oral tem vários projetos sobre a história do Distrito Federal e por isso permite desdobramentos temáticos: Memória da Construção de Brasília, Memória Fotográfica, Memória Filmográfica, Yvonne Jeane Jean, Comunicação e Arte, Política e sociedade, Brasília Palace Hotel, Formação de Taguatinga, Formação de Sobradinho, Formação de Planaltina, Formação do Núcleo Bandeirante e Formação da Ceilândia. O acervo é composto de 227 entrevistas com duração média de 1 hora e 40 minutos, além disso, há também três Cadernos de Pesquisa publicados contendo depoimentos de pioneiros de Planaltina, Núcleo Bandeirante e Ceilândia. ${ }^{45}$ Estes cadernos funcionam como meios de divulgação da documentação existente.

O projeto Memória da Construção está integrado no trabalho que o Arquivo Público do Distrito Federal tem em prol da preservação da memória brasiliense. Foi criado em 1987 e "tem por tema resgatar fontes sobre os aspectos técnicos e artísticos da construção de Brasília e elaborar documentos orais através do depoimento de arquitetos, engenheiros, calculistas, administradores e de pessoas que tiveram atuação marcante". ${ }^{46}$ Dessa forma se apresenta como um patrimônio de memória, e do espaço como meio de veicular esta; um suporte para a formação de uma memória coletiva. "A memória é o terreno onde cresce a história e por sua vez a alimenta, procura salvar o passado para servir ao presente e ao futuro". ${ }^{47}$ A partir do momento em que se trabalha não só com documentos, que retratam um passado distante, mas também com a (re)construção de memórias, coloca-se como possibilidade trazer para o plano do historiador o registro das próprias experiências, do vivido pelos sujeitos dos acontecimentos e dos fatos históricos.

O projeto articula-se com o esforço nacional de preservação da memória brasileira e se justifica pela necessidade de conhecer e estimular a preservação dos documentos que têm valor informativo sobre os aspectos técnicos e artísticos da construção de Brasília "Ele é proposto a partir da crítica à noção estigmatizante de que somos um povo sem memória e de que o Brasil é um país que não preserva as suas aquisições culturais." 48 O que estaria informando os organizadores do projeto nesse momento seria a possibilidade de resgatar a memória do passado através de lugares de memória e objetos que os rodeiam, assegurando e 
garantindo uma memória documental que serviria como referência do passado para a pesquisa histórica, assegurando a permanência através do tempo. Mostra a idéia de que para fazer história é necessário recorrer à memória e ao mesmo tempo sabe-se que ao fazer história constroe-se uma memória para o futuro.

Entre as justificativas do projeto está o interesse governamental em ressaltar a importância da cidade como um complexo arquitetônico de interesse universal e classificá-la como cidade monumento contemporâneo, daí uma outra intenção do projeto de dar substância arquivística e bibliográfica e propor o resgate dos registros técnicos artísticos da construção de Brasília. ${ }^{49}$ Essa intenção se concretizou em 7 de dezembro de 1987 quando a UNESCO transformou Brasília num Patrimônio Cultural da humanidade.

O projeto Memória da Construção apresenta a cidade de Brasília como fazendo parte de um projeto político de modernização do Estado Nacional, que havia iniciado no governo de Getúlio Vargas e teria como pano de fundo a ampliação dos mercados econômicos, a necessidade de integrá-lo e a lenta transformação de um país agrário em um país onde a indústria passasse a exercer um papel fundamental. Mostra a cidade como um fenômeno arquitetônico modernista dotado de um singular plano urbanístico e como o resultado da conjunção de forças históricas que traçaram o seu destino de metrópole urbana. Apresentando também uma cidade reduzida a uma organização do espaço urbano, materialidade monumental e a concretização de um projeto político realizado por Juscelino Kubitschek. ${ }^{50}$

O processo histórico de formação de Brasília e das configurações de seus diversos grupos sociais é apreendido a partir de um discurso onde à cidade é pensada como fazendo parte de uma entidade à parte de seus moradores, um fenômeno arquitetônico modernista dirigido pelas ações de grandes homens e assessorado por inúmeros outros que de alguma forma tiveram uma ação bem definida na construção da cidade. A história da cidade é concebida a partir de Juscelino Kubitschek:

Juscelino Kubitschek, com sua proposta desenvolvimentista, cristalizou o processo, levando à frente os planos e os sonhos, transformando-os em realidade, através do esforço ciclópico de alguns técnicos e artistas de rara competência, conjugado com o trabalho entusiástico de milhares de operários. Brasília nasceu como marco urbano do esforço de uma nação pobre para superar as marcas de seu passado colonial e como proposta de cidade onde a convivência humana seria baseada na fraternidade universal. Assim pensavam aqueles que a projetaram e a construíram. Nesse sentido, esta experiência adquire cunho universal. Tratou-se de um evento e de um momento especial onde fundiram-se a técnica e a arte com proposta histórico-política humanista e de valorização nacional. ${ }^{51}$ 
Como a cidade foi concebida dentro de um contexto nacional que buscava se afirmar internacionalmente e buscava os caminhos para o próprio desenvolvimento, a construção da cidade seria uma boa forma de provar a grandeza técnica e artística de homens que já haviam acumulado experiência e que transformaria Brasília num ponto obrigatório de referência reconhecida em escala planetária. "Entretanto as fontes arquivíticas para esse importante evento contemporâneo não foram objeto de providência global que garanta a sua preservação e permita seu uso sistemático, não foram completamente identificados ou referenciados e nem receberam qualquer tipo de tratamento". ${ }^{52}$

Os pontos de referência que estruturam a memória da construção e se inserem na memória da coletividade da cidade e que marca a força a partir do projeto, são pontos de referência como indicadores empíricos da memória coletiva, de um determinado grupo. Entre eles estão: a cidade como patrimônio arquitetônico e estilo monumental, as datas e os personagens históricos que são incessantemente lembrados, como por exemplo, Juscelino Kubitschek, Lúcio Costa, Oscar Niemeyer, Burle Mark e muitos outros "construtores" de Brasília.

Quando se decide o que é comum nesta cidade e em que se diferencia de outras e quando se diferenciam ações de um grupo de construtores heróis, se produz, segundo Pollak, uma memória estruturada com suas hierarquias e classificações, uma memória que ao definir o que é comum a um grupo e o que o diferencia de outros, fundamenta e reforça os sentimentos de pertencimento e as fronteiras sócio-culturais. ${ }^{53}$ Halbwachs, não vê nessa memória coletiva uma forma de dominação, diz que ela reforça a coesão social pela adesão afetiva ao grupo. Insinua, segundo Pollak, que há um processo de negociação para conciliar memória coletiva e memórias individuais. ${ }^{54}$

O projeto apresenta a necessidade de encontrar as fontes sobre a memória técnica e artística da construção da cidade de Brasília, que no momento de elaboração do projeto se encontravam dispersas. Então um dos objetivos é justamente, identificar esses documentos com a finalidade de recolher os originais daqueles cuja guarda compete ao Arquivo, obter cópias ou originais de documentos sobre os temas pertencentes a fundos de outros arquivos, públicos ou privados.

Um ponto forte desse projeto é registrar e arquivar o testemunho dos atores sociais diretamente envolvidos em todo o processo de criação e constituição da nova capital, através da metodologia e das técnicas da história oral. Lembrando que, as narrativas de história oral 
possibilitam analisar como uma pessoa significa sua experiência num dado momento de sua vida e situação de entrevista e como esta memória participa e sustenta uma leitura de seu tempo e de si mesma. A proposta do projeto é gravar depoimentos das pessoas que mais se destacaram e daquelas que colaboraram ou testemunharam mais proximamente os trabalhos de Lúcio Costa, Oscar Niemeyer, Burle Mark, Joaquim Cardoso, Bruno Giorgi, Marianne Peretti, Alfredo Ceschiatti, Athos Bulcão, dentre outros. ${ }^{55}$

Objetiva também "a criação de um banco de dados sobre os acervos bibliográficos e hemerográficos referentes ao tema, que seria alimentado sempre com novas informações, dinamizando-se ao centralizar e com isso facilitar as pesquisas sobre o assunto. (...) No momento, pensa-se que o ArPDF é o espaço físico-institucional indicado para a acumulação destes documentos." ${ }^{56}$ Como objetivo fim o projeto pretende

... a obtenção de medidas efetivas que levem à preservação e organização dos acervos arquivísticos referentes à construção de Brasília. Também consistirá na edição de instrumentos de pesquisa, em especial um Guia de Fontes e um Relatório, sobe o mesmo assunto. Ainda pode-se imaginar que a divulgação da existência e a abertura à consulta pública desses ${ }_{57}$ documentos é um serviço prestado ao desenvolvimento da cultura nacional.

O projeto privilegia a memória de um passado de homens de realização, com isso, no decorrer dos anos, a Instituição guarda e constrói registros de diferentes memórias. Realiza o trabalho de preservação da memória histórica da cidade, através da coleta de depoimentos (entrevistas), pautados em projetos pré-estabelecidos. Claro que nesses depoimentos se encontra memória, silêncios e esquecimentos, mas é bom lembrar que as entrevistas são temáticas e direcionadas com perguntas previamente formuladas e feitas com profissionais preparados. Observa-se que existe um estudo prévio sobre a história do entrevistado e um direcionamento, para aquilo que seria vocação do entrevistado. As entrevistas têm pontos de repetição, como dados biográficos, origem familiar, época que chegou em Brasília, mas, na continuidade da entrevista observa-se que existe direcionamento específico de entrevistado para entrevistado de acordo com a posição profissional, contatos de influência ou de trabalho com pessoas que seriam importantes, para o enquadramento da memória que se quer perpetuar, ou mesmo funções específicas que trariam dados importantes para serem lembrados.

Dessa forma é notável o interesse na existência de uma memória coletiva que resume a imagem que o projeto ou o Estado desejam passar e impor. Conforme as circunstâncias e a 
emergência de certas lembranças, a ênfase é dada a um ou outro aspecto. Nisso, há também uma permanente interação entre o vivido e o aprendido, o vivido e o transmitido. No processo dinâmico de constituição, eliminam-se interesses, estabelecem-se novos jogos de poder, cambiam-se os conteúdos da lembrança e do esquecimento, sempre formada pelos atores do presente, com base num repertório passado, com vistas a um futuro imaginado, desejado. ${ }^{58}$

Para que essa memória construída se consolide, se transforme num fundo comum de referências, um intenso trabalho de organização é indispensável. É necessário definir e reforçar sentimentos de pertencimento. Neste caso a referência ao passado serve para manter a coesão e interesse do grupo, fornecer um quadro de referências e de pontos de referência, daí a preocupação com a imagem de si e da história que é a sua razão de ser, ou seja, a memória da cidade como obra da ação de homens fortes, determinados a construir um modelo de cidade onde a solidariedade esteve muito presente. Dessa forma é preciso escolher testemunhos sóbrios e confiáveis para evitar que outros tomem a palavra e contem outra história. Quando são escolhidos os entrevistados com intenções pré-estabelecidas está sendo exercido um controle da memória pelos historiadores da casa, pela instituição.

Além da produção de discursos organizados, o trabalho do enquadramento da memória se dá também pelos objetos materiais: monumentos, bibliotecas, os fundos do Arquivo e a própria documentação escrita e oral adquirida pelo projeto de História Oral. Na medida em que a sociedade, os estudantes, pesquisadores, vão ao Arquivo e entram em contado com esses pontos de referências, adquirem um sentimento de adesão e pertencimento, ou mesmo de orgulho, por, de alguma forma fazer parte daquela história.

O Arquivo Público através de seu projeto Memória da Construção aponta para uma reflexão: o desejo de permanência, de guardar a memória da cidade desde a sua criação. As memórias individual e coletiva têm nos lugares uma referência importante para a sua construção, ainda que não seja condição para a sua preservação. As memórias dos grupos se referenciam, também, nos espaços em que habitam e nas relações que constroem com estes espaços. Foi falado anteriormente que faz parte dos objetivos do projeto, identificar os documentos com a finalidade de recolher os originais, criar de um banco de dados sobre os acervos bibliográficos e registrar e arquivar o testemunho dos atores sociais diretamente envolvidos em todo o processo de criação e constituição da nova capital, além da edição de instrumentos de pesquisa, em especial um Guia de Fontes e um Relatório, sobre o mesmo 
assunto para que o público possa ter acesso e o Arquivo preste um serviço ao desenvolvimento da cultura local e nacional.

O Arquivo Púbico é um lugar de memória, é um núcleo significativo, tanto da memória material como imaterial, sobre a criação da cidade de Brasília, para a memória e as identidades coletivas nesta cidade. Este núcleo se caracteriza por uma forte carga de simbolismo e emoção. Está arraigado nas convenções e costumes sociais, culturais e políticos do Distrito Federal e do Brasil e se modifica na medida em que mudam as maneiras de sua concepção, aprovação, uso e tradição. Os lugares de memória são estabilizadores da memória coletiva.

Para ajudar no enquadramento da memória coletiva, há preocupação com comemorações, aniversários do Arquivo, homenagens a pessoas importante na sua escala de interesses sem, no entanto se desprender do culto documental, já que tem um grande acervo e cuida com todos os cuidados estabelecidos pela ciência. Tem, inclusive uma publicação técnica, o Manual Básico de Conservação Preventiva do Arquivo Público do Distrito Federal que tem por finalidade promover a conscientização do pesquisador de arquivos, sobre a importância de ações preventivas para a salvaguarda dos acervos documentais. Também desenvolve atividades de divulgação do acervo textual e iconográfico, projetos, programas e eventos históricos junto aos seus usuários e na mídia. Há uma publicação da Série Textual Homens à Frente de seu Tempo, e também uma atividade chamada Governo Itinerante, onde durante uma semana, a população de uma Região Administrativa se torna o centro das atenções de todos os órgãos do GDF. No evento o governador e sua equipe ouvem as principais reivindicações dos moradores e promovem reuniões com lideranças comunitárias. O Arquivo Público participa com um Stand cujo objetivo é levar às comunidades um pouco da história do Distrito Federal.

Com essas atividades e esses espaços é possível o enquadramento da memória, obriga cada um a se relembrar e a reencontrar o pertencimento, princípio e segredo da identidade. São espaços criados e percebidos como parte importante na criação de uma memória coletiva, contribuindo assim, para a solidificação da memória. Essa memória não é construída pelo grupo, mas, para ele, para que este possa nela encontrar elementos que legitimem sua ação política no presente.

O Arquivo Público através de seu projeto Memória da Construção mostra o desejo de permanência, de guardar a memória da cidade desde a sua criação e demonstra que as 
memórias individuais e coletivas têm nos lugares uma referência importante para a sua construção, e preservação, sendo assim, as memórias dos grupos se referenciam, também, nos espaços em que habitam e nas relações que constroem com estes espaços, nas relações que constroem com o Arquivo, que é um lugar de memória material e imaterial e deixa claro que memória quer preservar, a memória de uma cidade construída com o esforço de vários homens, daquelas que colaborou ou testemunharam mais proximamente os trabalhos e com isso está valorizando uma memória política e dando embasamento para valorização de ações políticas individuais.

\section{NOTAS}

${ }^{1}$ PESAVENTO, Sandra Jatahy. História \& História Cultural. $2^{\mathrm{a}}$ ed. Belo Horizonte: Autêntica, 2005, p. 76.

${ }^{2}$ Idem, ibidem, p. 94.

${ }^{3}$ LE GOFF, J. História e Memória. Tradução Bernardo Leitão... [et al.] $5^{\mathrm{a}}$ ed. Campinas, SP, Editora da UNICAMP, 2003, p.419-471. BOSI, Ecléa. Memória e sociedade. Lembranças de velhos. São Paulo: T.A. Queiroz/EDUSP, 1987 p. 55. HALBWACHS, M. A memória Coletiva. São Paulo: Centauro, 2006 p. 7-16.

${ }^{4}$ POLLAK, M. "Memória e Identidade Social”. Estudos Históricos, v. 5, n.10, 1992 p. 9.

${ }^{5}$ HALBWACHS, M. A memória Coletiva. São Paulo: Centauro, 2006.

${ }^{6}$ Idem, ibidem, cap. 1.

${ }^{7}$ NORA, Pierre. Entre memória e história: a problemática dos lugares. Projeto História. São Paulo: PUC-SP. N ${ }^{\circ}$ 10, p. 12. 1993. Apud Arévalo, Márcia da Conceição de Massena. "Lugares de memória ou prática de preservar o invisível através do concreto". In www.anpuh.uepg.br, acesso em 10/11/2006.

${ }^{8}$ POLLAK, M. "Memória e Identidade ...”, op. cit., p. 4.

${ }^{9}$ LE GOFF, J. op. cit.,. p. 467.

${ }^{10}$ FERREIRA, Marieta de Moraes. História, Tempo presente e história oral. Topoi, Rio de Janeiro, dezembro, 2002 p, 21.

${ }^{11}$ BOSI, Ecléa. Memória e sociedade. Lembranças de velhos. São Paulo: T.A. Queiroz/EDUSP, 1987.

${ }^{12}$ KOSELLECK, Reinhart. Futuro passado: contribuição à semântica dos tempos históricos. Tradução de Wilma Patrícia Maas, Calda Almeida Pereira. Rio de janeiro: Contraponto: Ed. PUC - Rio, 2006.

${ }^{13}$ CATROGA, Fernando. "Memória e História" in: Pesavento, Sandra Jatahy (org.). Fronteiras do milênio. Porto Alegre: Ed. Universidade/UFRGS, 2001, p. $43-69$.

${ }^{14}$ POLLAK, M.. "Memória e Identidade...". op. Cit., p. 3.

${ }^{15}$ NORA, Pierre. Entre memória e história: a problemática dos lugares. Projeto História. São Paulo: PUC-SP. $\mathrm{N}^{\circ}$ 10, p. 12. 1993. Apud Arévalo, Márcia da Conceição de Massena. "Lugares de memória ou prática de preservar o invisível através do concreto". In www.anpuh.uepg.br), acesso em 11/11/2006.

${ }^{16}$ Idem, ibidem, 2.

${ }^{17}$ ARÉVALO, Márcia da Conceição de Massena. "Lugares de memória ou prática de preservar o invisível através do concreto". In www.anpuh.uepg.br) acesso em 10/11/2006.

${ }^{18}$ LE GOFF, op. cit.. p. 467.

${ }^{19}$ Idem, ibidem, p. 471.

${ }^{20}$ POLLAK, M. "Memória, Esquecimento, Silêncio". In: Estudos Históricos, vol. 2, n. 3. Rio de Janeiro, 1989.

${ }^{21}$ Idem, ibidem,. p. 202.

${ }^{22}$ HALL, Stuart. A Identidade em Questão. Horizontes, v. 23, n. 1, p. 67-76, jan./jun. 2005, p. 13.

${ }^{23}$ FERREIRA, Marieta de Moraes. p. 322-323.

${ }^{24}$ Idem, ibidem, p. 324.

${ }^{25}$ POLLAK, M. "Memória, Esquecimento...". p. 3.

${ }^{26}$ Dados tirados do Guia do Arquivo público do Distrito Federal. 5. ed. Ver.E aum. Brasília: ArPDF, 2004. p.33.

${ }^{27}$ Idem, ibidem, p. 17.

${ }^{28}$ Idem, ibidem, p. 17. 
${ }^{29}$ Idem, ibidem, p. 23.

${ }^{30}$ Idem, ibidem, p. 24.

${ }^{31}$ Idem, ibidem, p. 25.

${ }^{32}$ Idem, ibidem, p. 26.

${ }^{33}$ Idem, ibidem, p. 30.

${ }^{34}$ Idem, ibidem, p. 30.

${ }^{35}$ Idem, ibidem, p. 24.

${ }^{36}$ Idem, ibidem, p. 24.

${ }^{37}$ Idem, ibidem, p. 28.

${ }^{38}$ SQS significa Setor de Quadras Sul.

${ }^{39}$ Idem, ibidem, p. 29.

${ }^{40}$ Idem, ibidem, p. 27.

${ }^{41}$ Idem, ibidem, p. 21.

${ }^{42}$ Idem, ibidem, p. 21.

${ }^{43}$ http://www.arpdf.df.gov.br/, acesso em 06/11/2006.

${ }^{44}$ Idem, ibidem.

${ }^{45}$ Guia do Arquivo público do Distrito Federal, p. 22.

${ }^{46}$ Idem, ibidem, p. 471.

${ }^{47}$ Idem, ibidem, p. 471.

${ }^{48}$ PROJETO MEMÓRIA DA CONSTRUÇÃO DE BRASÍLIA.. op. cit. p. 34.

${ }^{49}$ Idem, ibidem, p. 34.

${ }^{50}$ Idem, ibidem, p. 22.

${ }^{51}$ Idem, ibidem, p. 22.

${ }^{52}$ Idem, ibidem, p. 24.

${ }^{53}$ POLLAK, M. "Memória, Esquecimento..." op. cit., p.1.

${ }^{54}$ Idem, ibidem, p. 1.

${ }^{55}$ PROJETO MEMÓRIA DA CONSTRUÇÃO DE BRASÍLIA. op. cit., p. 30.

${ }^{56}$ Idem, ibidem, p. 31.

${ }^{57}$ Idem, ibidem, p. 32.

${ }^{58}$ POLLAK, M. "Memória, Esquecimento...” op. cit., p. 8. 